\title{
Role of diffusion weighted MR-imaging in the evaluation of malignant mediastinal lesions
}

\author{
Youssriah Yahia Sabri', Eman Zaki Bassyouni Nossair ${ }^{2 *}$ (D) HebatAllah Hany Assal ${ }^{3}$ and Hisham Samir Wahba ${ }^{4}$
}

\begin{abstract}
Background: Conducted studies showed that the ADC (apparent diffusion coefficient) values of malignant mediastinal lesions are significantly lower than those of benign lesions. Investigators determined cut-off ADC values to differentiate the two; concluding that ADC value is a promising noninvasive, imaging parameter that helps assess and characterize mediastinal tumors.

Taking this a step forward, the primary objective of our prospective study was to investigate the potential of DWMRI (diffusion-weighted magnetic resonance imaging) to characterize malignant mediastinal lesions using their ADC values.

Thirty-three patients that underwent MRI of the chest with DWI and latter pathologically diagnosed with a malignant mediastinal lesion were included in this study. Lesions' ADC values were measured and correlated with the histopathological results. The statistical significance of differences between measurements was tested using the one-way ANOVA (analysis of variance) test; $p$ values equal to or less than 0.05 were considered significant.

Results: There was no statistically significant difference between the $A D C_{\text {mean }}$ values of the histopathological groups of lesions assessed with the overlap of their $A D C_{\text {mean }}$ values. The average $A D C_{\text {mean }}$ value of $\mathrm{NHL}$ (nonHodgkin lymphoma) was evidently lower than that of HD (Hodgkin disease) with no overlap between their $A D C_{\text {mean }}$ values. DWl failed at characterizing one lesion in this study as a malignant tumor, namely an immature teratoma (germ-cell tumor). Again DWI could not be used to evaluate a mass, latter pathologically diagnosed as an angiosarcoma, because of its overall hemorrhagic nature showing no definite non-hemorrhagic soft tissue components. The aforementioned results did not differ considerably when minimum ADC was used instead of mean ADC.

Conclusion: There was no statistically significant difference between the ADC values of the malignant mediastinal lesions evaluated. However, regarding lymphoma subtypes, our limited sample study of lymphoma suggested a considerable difference between the ADC values of Hodgkin disease and non-Hodgkin lymphoma.
\end{abstract}

Keywords: Malignant mediastinal lesions, DWI (diffusion-weighted imaging), ADC (apparent diffusion coefficient)

\section{Background}

The mediastinum comprises the thoracic compartment anatomically bounded by the thoracic inlet superiorly, the diaphragm inferiorly, the posterior sternal border anteriorly, and posteriorly by the vertebral column. It is an intricate segment of the thorax that contains vital intra-thoracic structures

\footnotetext{
*Correspondence: eman.zaki5@gmail.com

${ }^{2}$ Radiodiagnosis, National Hepatology and Tropical Medicine Research

Institute (NHTMRI), 10 (A) Kasr El-Aini St, Cairo, Egypt

Full list of author information is available at the end of the article
}

such as the heart and great vessels, trachea and main bronchi, esophagus, thymus, venous and lymphatic structures, and nerve tissue. Lesions of the mediastinum span a wide histopathological and radiological spectrum. Both anatomical information (location) and internal characteristics (composition) are essential to formulate the differential diagnosis of a mass in the mediastinum and therefore determine therapeutic options [1-3].

A cross-sectional imaging-based classification that divides the mediastinum into anterior (prevascular), middle 
(visceral), and posterior (paravertebral) compartments was recently published by the International Thymic Malignancy Interest Group (ITMIG). Contents of each mediastinal compartment, as well as the most commonly encountered lesions, are reviewed in Table 1 [4].

Computed tomography (CT) is considered the imaging modality of choice for evaluating most mediastinal masses; however, the role of magnetic resonance (MR) imaging continues to expand given its high soft-tissue contrast. It is superior to CT in differentiating between cystic and solid masses, identifying cystic and solid components within complex lesions, and distinguishing thymic hyperplasia and normal thymus from thymic epithelial neoplasms and other neoplasms-the result is added diagnostic specificity or virtual biopsy of the lesion. Assessment of preoperative relationships with the pericardium, heart cavities, spinal cord, and vascular involvement is a common indication of MR imaging of a mediastinal lesion [6].

With the recent advances in MR systems, DW-MRI (diffusion-weighted magnetic resonance imaging) of the thoracic cavity has become possible with fast imaging time that minimizes the effect of gross physiological motion from respiration and cardiac movement. DWI, a non-contrast functional MR imaging technique, allows the analysis of tissue characteristics based on the diffusivity of water molecules within tissues. Quantitative assessment of a tumor is possible by calculating its apparent diffusion coefficient (ADC) value which is inversely correlated with tissue cellularity. Hence, DWI has been proposed as a cancer biomarker with the diagnostic potential to distinguish benign from malignant tumors because of the tendency of the latter to show more restricted diffusion, i.e., lower ADC values (Table 2) [9-12].

Studies, conducted over the past few years, showed that the ADC values of malignant mediastinal lesions are significantly lower than those of benign lesions and determined cut-off ADC values to differentiate the two; concluding that $\mathrm{ADC}$ value is a promising noninvasive, imaging parameter that helps assess and characterize mediastinal tumors. Further studies were recommended [11, 13-17].

Thereby, the primary objective of this prospective study was to further investigate the potential of DW-MRI to characterize malignant mediastinal lesions using their ADC values; in an attempt to improve non-invasive approaches by which patients with mediastinal lesions are diagnosed/managed. On searching the literature, no studies, aiming primarily to differentiate between the various pathological types of malignant mediastinal lesions using DWI, were found.

\section{Methods \\ Subjects}

- Institutional ethical clearance was taken before conducting this prospective study.

- Written consent was obtained from patients or their authorized representatives.

- Forty-eight patients (29 males and 19 females; age range: 2 to 73 years; mean age $=40$ years) presenting

Table 1 Contents of each mediastinal compartment and the most commonly encountered lesions $[1,4,5]$

\begin{tabular}{|c|c|c|}
\hline Compartment & Major contents & Common lesions \\
\hline Anterior (prevascular) & $\begin{array}{l}\text { Thymus } \\
\text { Fat } \\
\text { Lymph nodes } \\
\text { Left brachiocephalic vein }\end{array}$ & $\begin{array}{l}\text { - Thymic lesions/masses } \\
\text { - Germ cell neoplasms } \\
\text { - Lymphoma } \\
\text { - Intra-thoracic goiter } \\
\text { - Metastatic lymphadenopathy } \\
\text { (50\% of all mediastinal masses) }\end{array}$ \\
\hline Middle (visceral) & $\begin{array}{l}\text { Non-vascular: } \\
\text { trachea, carina, esophagus, lymph nodes } \\
\text { Vascular: } \\
\text { heart, aorta, } \\
\text { superior vena cava, intra-pericardial pulmonary } \\
\text { arteries, thoracic duct }\end{array}$ & $\begin{array}{l}\text { - Lymphoma } \\
\text { - Metastatic lymphadenopathy } \\
\text { - Foregut duplication cysts } \\
\text { - Tracheal lesions } \\
\text { - Esophageal masses } \\
\text { - Aortic aneurysms } \\
\text { - Cardiac masses } \\
\text { - Pericardial masses/cysts } \\
\text { (Congenital cysts are the most common) }\end{array}$ \\
\hline \multirow[t]{2}{*}{ Posterior (para-vertebral) } & Paravertebral soft tissues & $\begin{array}{l}\text { - Benign and malignant peripheral nerve sheath tumors } \\
\text { - Sympathetic ganglia tumors } \\
\text { - Lateral thoracic meningocele } \\
\text { - Extramedullary hematopoiesis } \\
\text { (Neurogenic tumors are the most common) }\end{array}$ \\
\hline & & $\begin{array}{l}\text { Central bronchogenic carcinoma may be allocated to/involve } \\
\text { any one or more of the three mediastinal compartments. }\end{array}$ \\
\hline
\end{tabular}


Table 2 Qualitative (Visual) assessment of DW images: signal intensities seen in the high b value images and corresponding ADC maps $[7,8]$

Facilitated diffusion (e.g. benign cyst)
Restricted diffusion (e.g. malignant tumor)
Pitfalls of DWI 2 - Shine through effect
E.g. a cyst will demonstrate high signal intensity on T2-weighted images and on diffusion images obtained
at high b values but also on the ADC map. Unlike a cyst, a region with truly restricted diffusion will
demonstrate low signal intensity on the ADC map.

Slow-flowing blood within a region may demonstrate the signal intensity characteristics of a highly cellular lesion. This pitfall is readily observed on DWI of a hemangioma. In this situation, interpretation of the findings obtained with other MR sequences is very helpful.

with a mediastinal mass recently identified on CT were referred from the Thoracic Surgical Oncology Clinic to the Radiology Department of National Cancer Institute for MRI of the chest with DWI over a period of 20 months (February 2016 to October 2017). After MR imaging, patients were scheduled for biopsy and histopathological diagnosis.

- Inclusion criteria:

- Patients with a mediastinal lesion identified on CT.

- Exclusion criteria:

- Patients with contraindications to MRI including pacemakers, cochlear implants, cerebral aneurysm clips, ocular metallic foreign body, and bullets or shrapnel near great vessels or vital organs.
- History of previous biopsy/treatment of the mediastinal mass.

- Patients whose images showed motion artifacts $(n=2)$.

- Patients with pathologically proven benign mediastinal lesions $(n=10)$ or indeterminate pathological diagnosis $(n=3)$.

\section{Methods \\ MRI of the chest with DWI (image acquisition and evaluation)}

1. Image acquisition: MRI of the chest with DWI was done for all patients with a 1.5 Tesla unit (Achieva; Philips Medical Systems, Best, The Netherlands) using a 16-channel phased array

Table 3 MR imaging parameters

\begin{tabular}{llllll}
\hline & TR/TE $(\mathrm{ms})$ & $\begin{array}{l}\text { Direction of frequency } \\
\text { encoding }\end{array}$ & Section thickness $(\mathrm{mm})$ & Inter-slice gap $(\mathrm{mm})$ & FOV $(\mathrm{mm})$ \\
\hline Axial T1-WI (TSE) & $10 / 4.6$ & AP & 9 & 2 & $420 \times 325 \times 306212 \times 179$ \\
Coronal T1-WI (TSE) & $10 / 4.6$ & R/L & 9 & 1.5 & $425 \times 425 \times 208284 \times 246$ \\
Axial T2-WI (TSE) & $738 / 100$ & AP & 9 & 2 & $420 \times 325 \times 306248 \times 167$ \\
Coronal T2-WI (TSE) & $738 / 100$ & R/L & 9 & 1.5 & $425 \times 425 \times 208284 \times 246$ \\
Sagittal T2-WI (TSE) & $738 / 100$ & AP & 8.5 & 1 & $400 \times 299 \times 284268 \times 195$ \\
STIR-WI & $1788.3 / 20$ & AP & 10 & 2 & $450 \times 333 \times 334216 \times 161$
\end{tabular}

DWI (SS-SE-EPI-with fat suppression) DWI were acquired in a transverse plane, using three $b$ values: low $\left(0-50 \mathrm{~s} / \mathrm{mm}^{2}\right)$, intermediate $\left(500 \mathrm{~s} / \mathrm{mm}^{2}\right)$ and high $b$ value $\left(1000 \mathrm{~s} / \mathrm{mm}^{2}\right)$.
$1407 / 66.5$ AP
9
$420 \times 324 \times 306 \quad 140 \times 107$

ADC map

ADC maps were calculated by the MR system via linear regression analysis of the natural log of signal intensity using all three $b$ values

Abbreviations: TR: repetition time, TE: echo time, FOV: Field-of-view, WI: Weighted image, TSE: Turbo spin echo, STIR: Short tau inversion recovery, R/L: Right to left, $A / P$ : Antero-posterior, SS-SE-EPI: Single-shot spin-echo echo-planar imaging 
torso coil (Sense XL Torso; Philips Healthcare) to acquire axial and coronal unenhanced T1-WI, axial, coronal and sagittal T2-WI, and axial STIR and DWI. Respiratory triggering was used. MR imaging parameters are listed in Table 3.

2. Image evaluation: MR images were qualitatively analyzed by means of visual assessment of the different pulse sequences and quantitatively assessed by measuring the ADC values of the depicted mediastinal lesions.

2.1 Qualitative assessment:
The following was recorded:

- Lesions' location (anterior, middle, and posterior mediastinum), morphological features (e.g., shape and margin) as well as the extent and relations to adjacent structures.

- Signal intensity on the T1, T2, and STIR WI relative to that of muscles in the same pulse sequence. Signal intensity on the high $b$ value $(b=1000 \mathrm{~s} /$ $\mathrm{mm}^{2}$ ) DWI and corresponding ADC map.

- Associated MR imaging findings, e.g., pleural effusion.

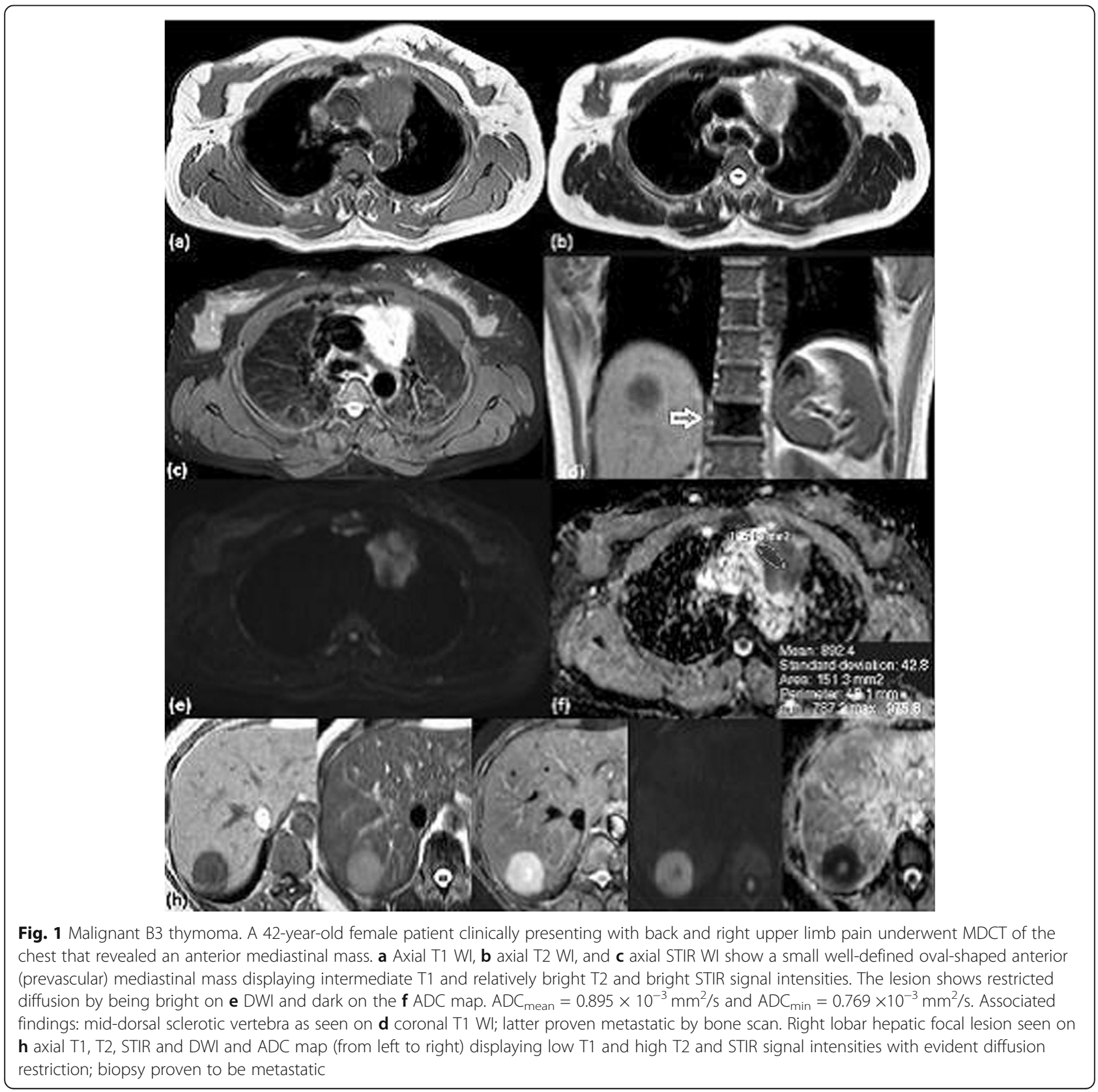




\subsection{Quantitative assessment:}

ADC values were measured by placing a ROI (region of interest) within the lesion on the trace ADC maps. ROIs were positioned within areas visually judged to be the most restricted (excluding obviously cystic/necrotic areas). To avoid image selection bias, three ROIs were placed on at least three sections (cranial, middle, and caudal portions) within the lesion whenever possible and average mean and minimum $\mathrm{ADC}$ values $\left(\mathrm{ADC}_{\text {mean }}\right.$ and $\left.\mathrm{ADC}_{\text {min }}\right)$ were calculated.

\section{Histopathological diagnosis}

Taking both lesion accessibility and patients' general condition into account, patients underwent U/S or CT-guided biopsies, bronchoscopy, mediastinoscopy, or thoracotomy.

Consequently, 33 patients pathologically diagnosed with a malignant mediastinal lesion were included in the study; 21 males (63.6\%) and 12 females (36.4\%) with age range 10 to 73 years (mean age 42.18 years).

\section{Statistical/data analysis}

Data was coded and entered using the statistical package SPSS version 21. It was summarized using descriptive

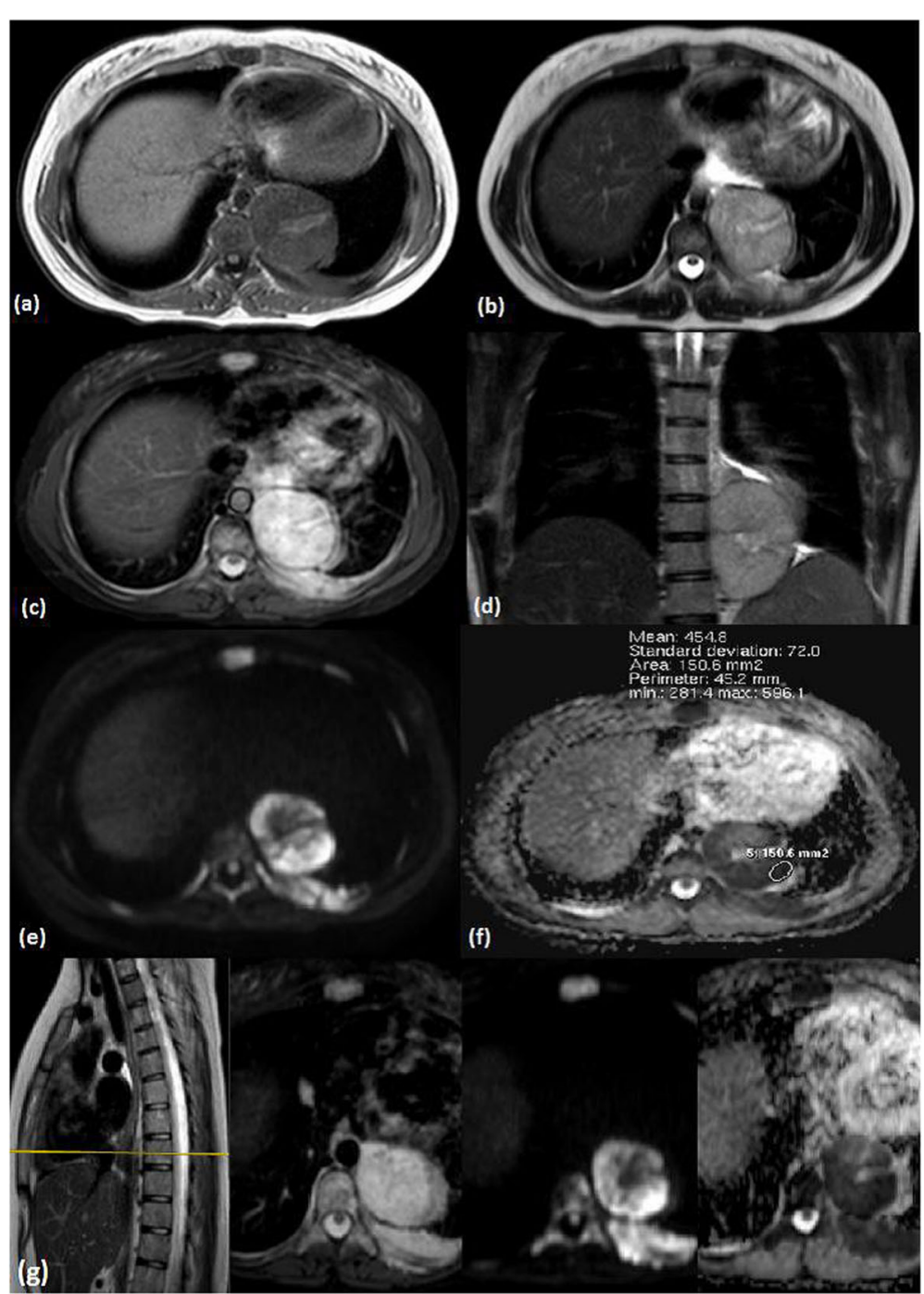

Fig. 2 Ganglioneuroblastoma: A 16-year-old female with a posterior mediastinal (left paravertebral) mass identified on CT. The patient clinically presented with dorsal back pain radiating to the right upper limb and bilateral hip pain with a history of blood transfusion to correct anemia. a Axial T1 WI, b and $\mathbf{d}$ axial and coronal T2 WI and c STIR WI show a well-defined oval-shaped posterior mediastinal (left paravertebral) mass displaying intermediate $\mathrm{T} 1$ and bright T2 and STIR signal intensities with a central scar showing bright signal on all three pulse sequences. Mass is centered on the adjacent neural exit foramina with no definite neural foraminal or intraspinal extension. Invasion of the posterior aspects of the adjacent ribs is seen in the form of soft tissue encasement. Associated patchy altered MR marrow signal of the examined bones is seen most evident on $\mathbf{g}$ axial STIR and DWI and the ADC map (from left to right). The mass shows restricted diffusion by being bright on $\mathbf{e}$ DWI and dark on the $\mathbf{f} A D C$ map: $A D C_{\text {mean }}=0.473 \times 10^{3} \mathrm{~mm}^{2} / \mathrm{s}$ and $A D C_{\text {min }}=0.327 \times 10^{-3} \mathrm{~mm}^{2} / \mathrm{s}$ 


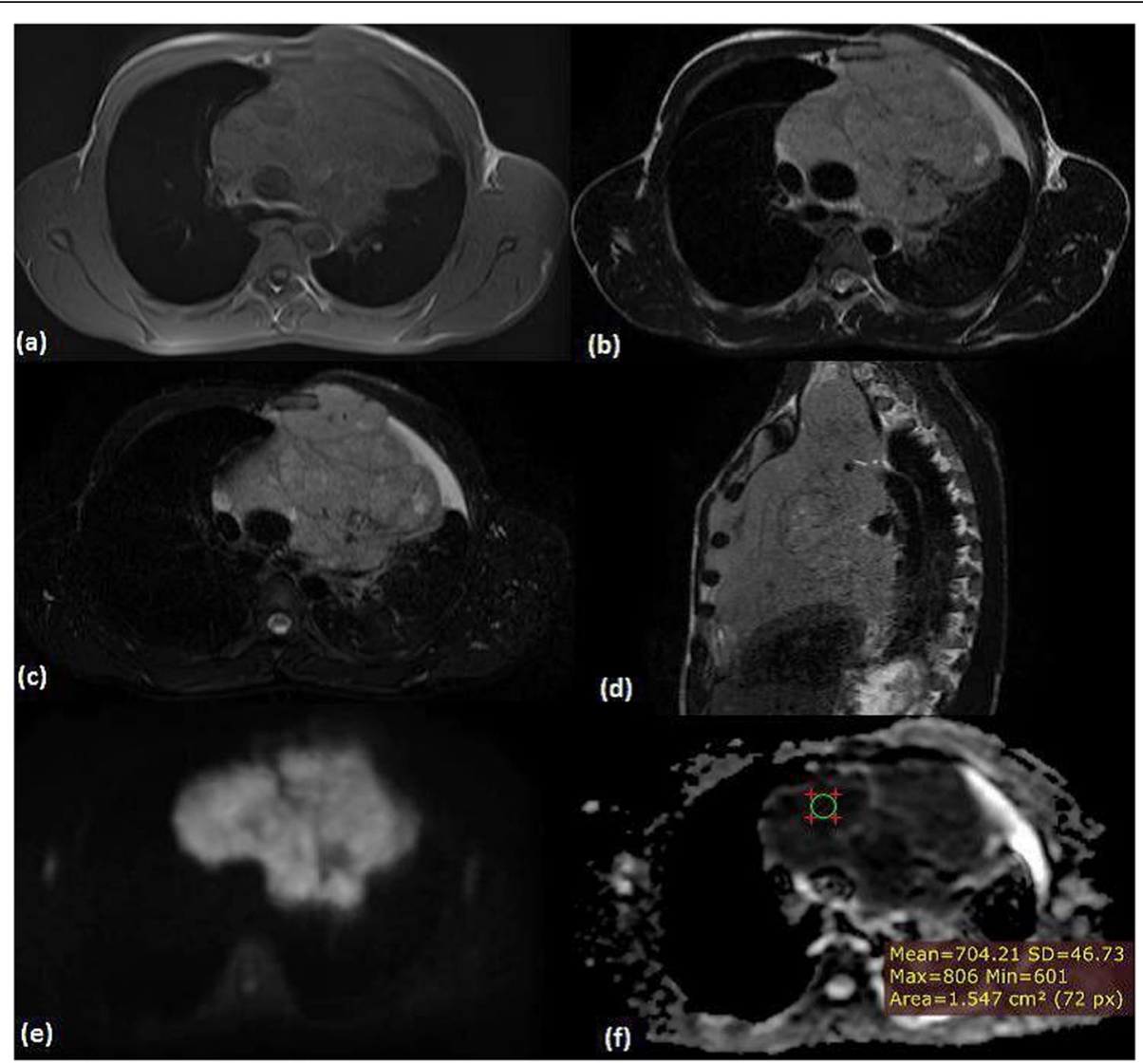

Fig. 3 Seminoma: 30-year-old male with an anterior (prevascular) mediastinal mass identified on $\subset$ T. The patient clinically presented with dyspnea and chest pain. a Axial T1 WI, b axial T2 WI, c axial STIR WI, and $\mathbf{d}$ sagittal T2 WI show a large well-defined macro-lobulated anterior mediastinal mass displaying rather homogeneous intermediate T1, relatively bright T2 and bright STIR signal intensities. The mass shows restricted diffusion; with the predominant bright areas on the $\mathbf{e} D W l$ corresponding to dark areas on the $\mathbf{f} A D C$ map: $A D C_{\text {mean }}=0.615 \times 10^{-3} \mathrm{~mm}^{2} / \mathrm{s}$ and $A D C_{\min }=0.494 \times 10^{-3} \mathrm{~mm}^{2} / \mathrm{s}$

statistics: number and percentage for qualitative values and mean and standard deviation and median and interquartile range for quantitative variables. One-way ANOVA (analysis of variance) test was used to compare means. $p$ values equal to or less than 0.05 were considered significant. Data was presented by Box-Plot graphs, bar charts, histograms, pie charts as well as tables.

\section{Results}

- Lesions were grouped according to their histopathological diagnosis into lymphoma
( $n=9 ; 27.3 \%)$, bronchogenic carcinoma $(n=10$; $30.3 \%)$, metastatic lymph nodes $(n=4 ; 12.1 \%)$, thymic tumors $(n=4 ; 12.1 \%)$, germ cell tumors ( $n=4 ; 12.1 \%)$, neurogenic tumors $(n=1 ; 3.03 \%)$, and angiosarcoma ( $n=1 ; 3.03 \%)$ (Figs. 1,2 and 3 ).

- Lesions were allocated to one or more mediastinal compartments according to the cross-sectional-based mediastinal classification system recently published by the ITMIG as shown in Table 4 .

- The range of $\mathrm{ADC}_{\text {mean }}$ and $\mathrm{ADC}_{\text {min }}$ values of lesions in each histopathological group, as well

Table 4 Lesions allocated to mediastinal compartments

\begin{tabular}{|c|c|c|c|c|c|c|c|c|}
\hline Mediastinal compartment & Lymphoma & $\begin{array}{l}\text { Central bronchogenic } \\
\text { carcinoma }\end{array}$ & $\begin{array}{l}\text { Metastatic } \\
\text { lymph nodes }\end{array}$ & $\begin{array}{l}\text { Thymic } \\
\text { tumors }\end{array}$ & $\begin{array}{l}\text { Germ cell } \\
\text { tumors }\end{array}$ & $\begin{array}{l}\text { Neurogenic } \\
\text { tumors }\end{array}$ & Angiosarcoma & Total \\
\hline Anterior & 7 & 1 & 2 & 4 & 4 & - & 1 & $19(57.6 \%)$ \\
\hline Middle & - & 4 & 2 & - & - & - & - & $6(18.2 \%)$ \\
\hline Posterior & - & - & - & - & - & 1 & - & $1(3 \%)$ \\
\hline More than one compartment & 2 & 5 & - & - & - & - & - & $7(21.2 \%)$ \\
\hline Total & 9 & 10 & 4 & 4 & 4 & 1 & 1 & $33(100 \%)$ \\
\hline
\end{tabular}


Table 5 Summary of $A D C_{\text {mean }}$ and $A D C_{\text {min }}$ values per histopathological group

\begin{tabular}{|c|c|c|c|}
\hline $\begin{array}{l}\text { Pathological } \\
\text { entity }\end{array}$ & $\begin{array}{l}\text { Number of cases } \\
\text { and percentage (\%) }\end{array}$ & $\begin{array}{l}\mathrm{ADC}_{\text {mean }} \text { range } \\
\text { average } \pm \mathrm{SD}^{*}\end{array}$ & $\begin{array}{l}A D C_{\min } \text { range } \\
\text { average } \pm S D^{*}\end{array}$ \\
\hline Lymphoma & $9(27.3 \%)$ & $\begin{array}{l}(0.507-1.08) \\
0.733 \pm 0.191\end{array}$ & $\begin{array}{l}(0.343-0.846) \\
0.541 \pm 0.164\end{array}$ \\
\hline $\begin{array}{l}\text { Central } \\
\text { bronchogenic } \\
\text { carcinoma }\end{array}$ & $10(30.3 \%)$ & $\begin{array}{l}(0.501-1.633) \\
0.904 \pm 0.342\end{array}$ & $\begin{array}{l}(0.354-1.474) \\
0.747 \pm 0.336\end{array}$ \\
\hline $\begin{array}{l}\text { Metastatic } \\
\text { lymph nodes }\end{array}$ & $4(12.1 \%)$ & $\begin{array}{l}(0.667-1.391) \\
1.033 \pm 0.3\end{array}$ & $\begin{array}{l}(0.467-1.212) \\
0.822 \pm 0.307\end{array}$ \\
\hline Thymic tumors & $4(12.1 \%)$ & $\begin{array}{l}(0.847-1.233) \\
0.959 \pm 0.184\end{array}$ & $\begin{array}{l}(0.708-1.111) \\
0.827 \pm 0.191\end{array}$ \\
\hline Germ cell tumors & $4(12.1 \%)$ & $\begin{array}{l}(0.568-2.44) \\
1.058 \pm 0.921\end{array}$ & $\begin{array}{l}(0.431-1.701) \\
0.776 \pm 0.616\end{array}$ \\
\hline Neurogenic tumors & $1(3.03 \%)$ & 0.473 & 0.327 \\
\hline Angiosarcoma & $1(3.03 \%)$ & \multicolumn{2}{|c|}{ Could not be measured ${ }^{* *}$} \\
\hline Total & $33(100 \%)$ & $0.884 \pm 0.396$ & $0.699 \pm 0.326$ \\
\hline
\end{tabular}

as their arithmetic means (averages), are shown in the Table 5.

- There was no statistically significant difference between the $\mathrm{ADC}_{\text {mean }}$ values of the histopathological groups of lesions assessed ( $p$ value $>0.05$ ). Overlap of their $\mathrm{ADC}_{\text {mean }}$ values is demonstrated on the Barand-Whisker plot (Fig. 4).
- Since lymphoma and bronchogenic carcinoma were the two most prevalent lesions in our study, the following was considered:

- Average $\mathrm{ADC}_{\text {mean }}$ of lymphoma was evidently lower than that of bronchogenic carcinoma; however, no statistically significant difference was found between their $\mathrm{ADC}_{\text {mean }}$ values ( $p$ value $>0.05$ ).

- Average $\mathrm{ADC}_{\text {mean }}$ value of lymphoma was the lowest when compared to those of bronchogenic carcinoma, metastases, thymic, and germ cell tumors. Yet, there was no statistically significant difference between the $\mathrm{ADC}_{\text {mean }}$ values of lymphoma and the $\mathrm{ADC}_{\text {mean }}$ values of these histopathological groups conjointly ( $p$ value $>0.05$ ).

- Similarly, there was no statistically significant difference between the $\mathrm{ADC}_{\text {mean }}$ values of bronchogenic carcinoma and the $\mathrm{ADC}_{\text {mean }}$ values of the other malignant mediastinal lesions all together ( $p$ value $>0.05$ )

- In the context of mediastinal compartments, anterior mediastinal lesions were the most prevalent in our study, representing $57.6 \%$ of lesions. The lesions most importantly included lymphoma, thymic, and germ cell tumors (in ascending order of average $\mathrm{ADC}_{\text {mean }}$ values). Difference between their $A D C$ values was, however, statistically insignificant $(p$ value $>0.05)$.

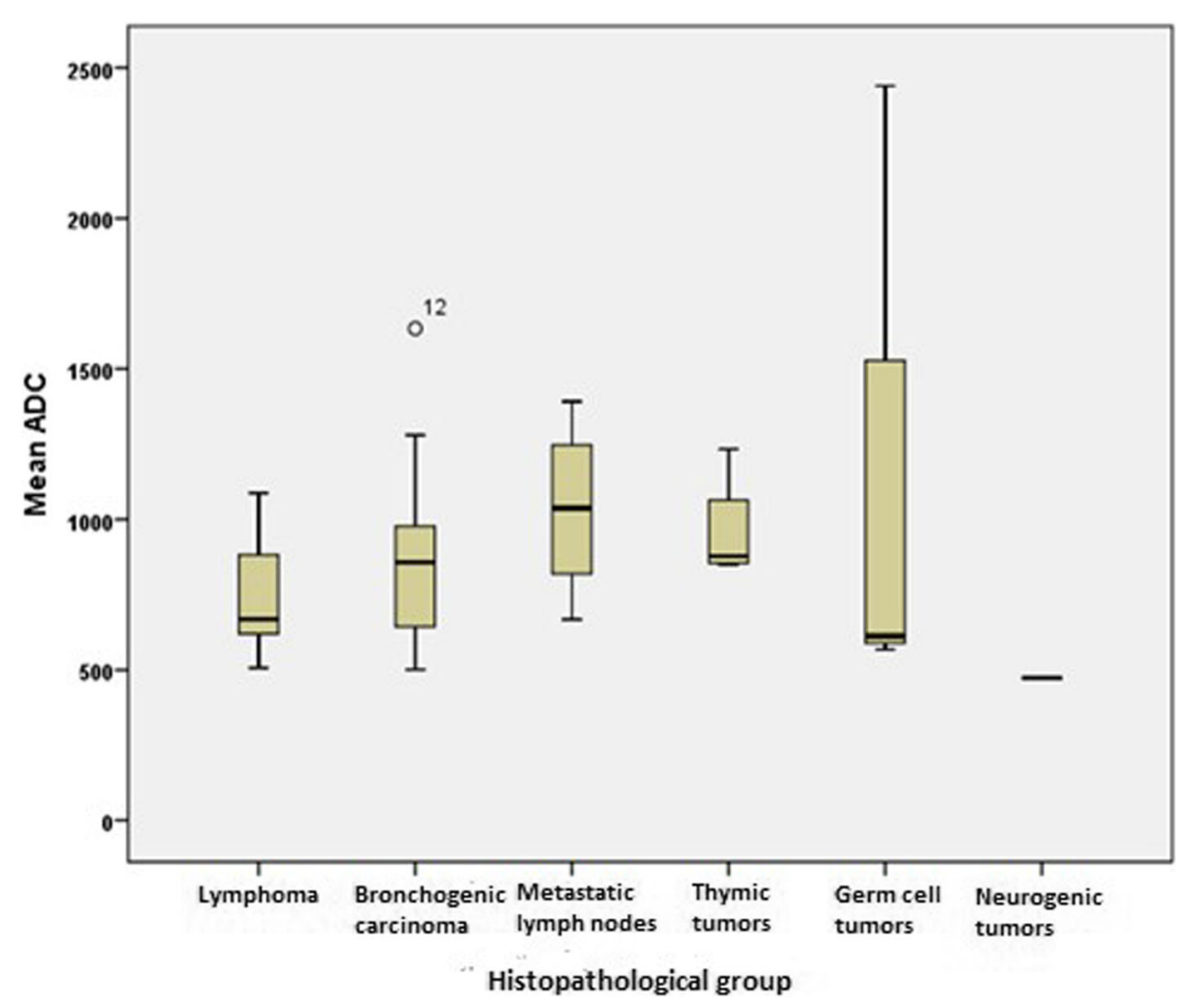

Fig. 4 Bar-and-Whisker plot: $A D C_{\text {mean }}$ values of the different histopathological groups 
- Each histopathological group was studied distinctly and the following was recognized:

- Among the nine patients, pathologically diagnosed as lymphoma; five had non-Hodgkin lymphoma
(NHL) and four had Hodgkin lymphoma (HD)

(Figs. 5 and 6). The average $\mathrm{ADC}_{\text {mean }}$ value of NHL was evidently lower than that of HD with no overlap between their $\mathrm{ADC}_{\text {mean }}$ values on the

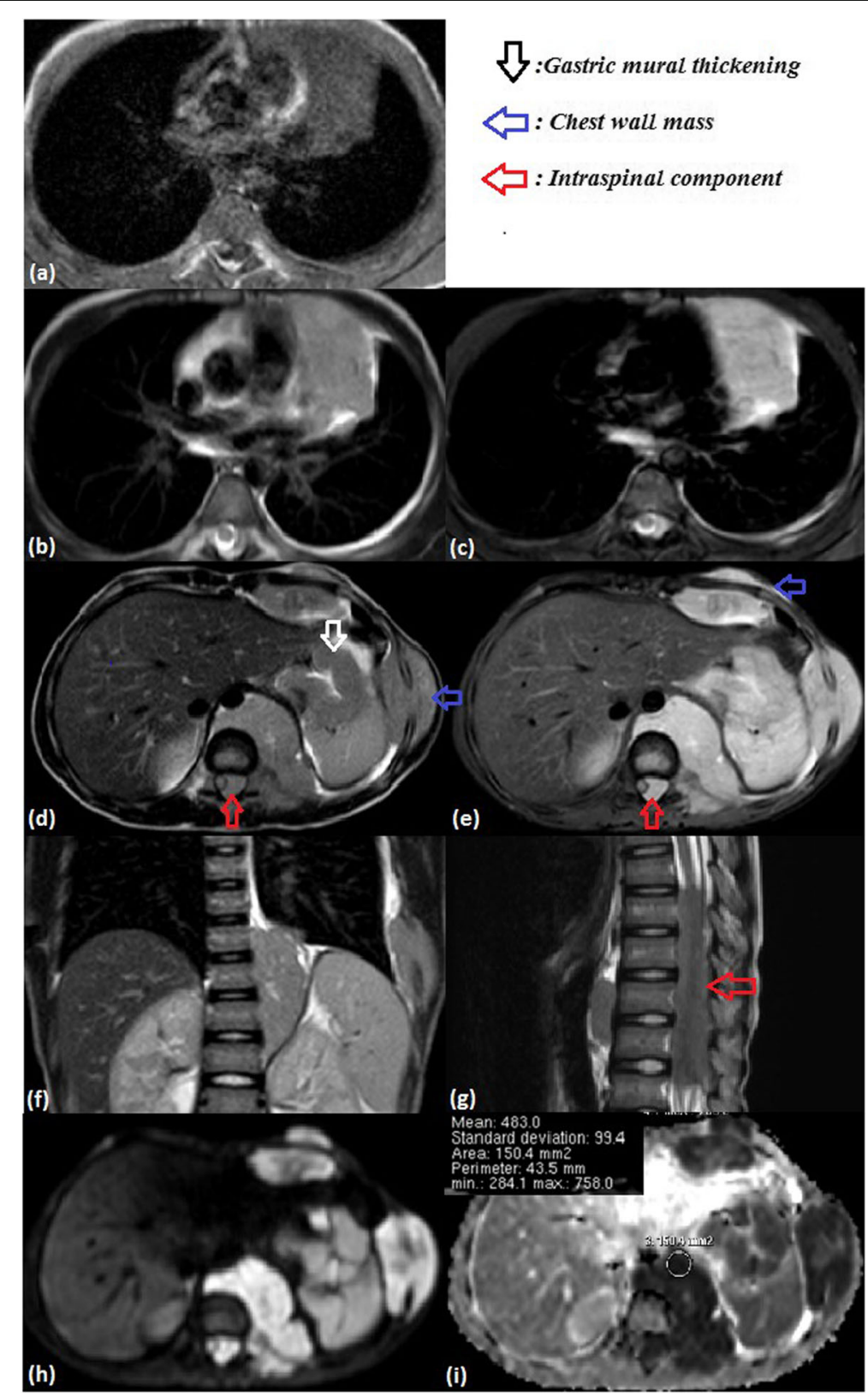

Fig. $5 \mathrm{NHL}$ (Burkitt lymphoma): A 13-year-old male clinically presenting with constitutional symptoms (anorexia and weight loss) and left parasternal and left lateral lower chest wall swellings. a Axial T1 WI, b axial T2 WI, and $\mathbf{c}$ axial STIR WI show a well-defined rather ovoid-shaped anterior mediastinal mass displaying intermediate T1, relatively bright T2 and bright STIR signal intensities. d Axial T2 WI, e axial STIR WI, and f coronal T2 WI show another oblong-shaped posterior mediastinal (left paravertebral) mass displaying similar signal characteristics. It extends from the level of D9 down to D12 vertebra. Intraspinal extension in the form of a large epidural soft tissue component is seen opposite D7/8 down to D12 vertebra on the $\mathbf{g}$ sagittal T2 WI with evident displacement and compression of the dorsal cord. The lesions show restricted diffusion by being bright on the $\mathbf{h}$ DWI and dark on the $\mathbf{i} A D C$ map: $A D C_{\text {mean }}=0.507 \times 10^{-3} \mathrm{~mm}^{2} / \mathrm{s}$ and $A D C_{\min }=0.343 \times 10^{-3} \mathrm{~mm}^{2} / \mathrm{s}$. Associated findings: left parasternal and left lateral lower chest wall soft tissue lesions (seen encasing the related ribs). The upper abdominal cuts revealed circumferential gastric mural thickening. Both display similar signal characteristics to the aforementioned mediastinal masses. Minimal left pleural effusion 


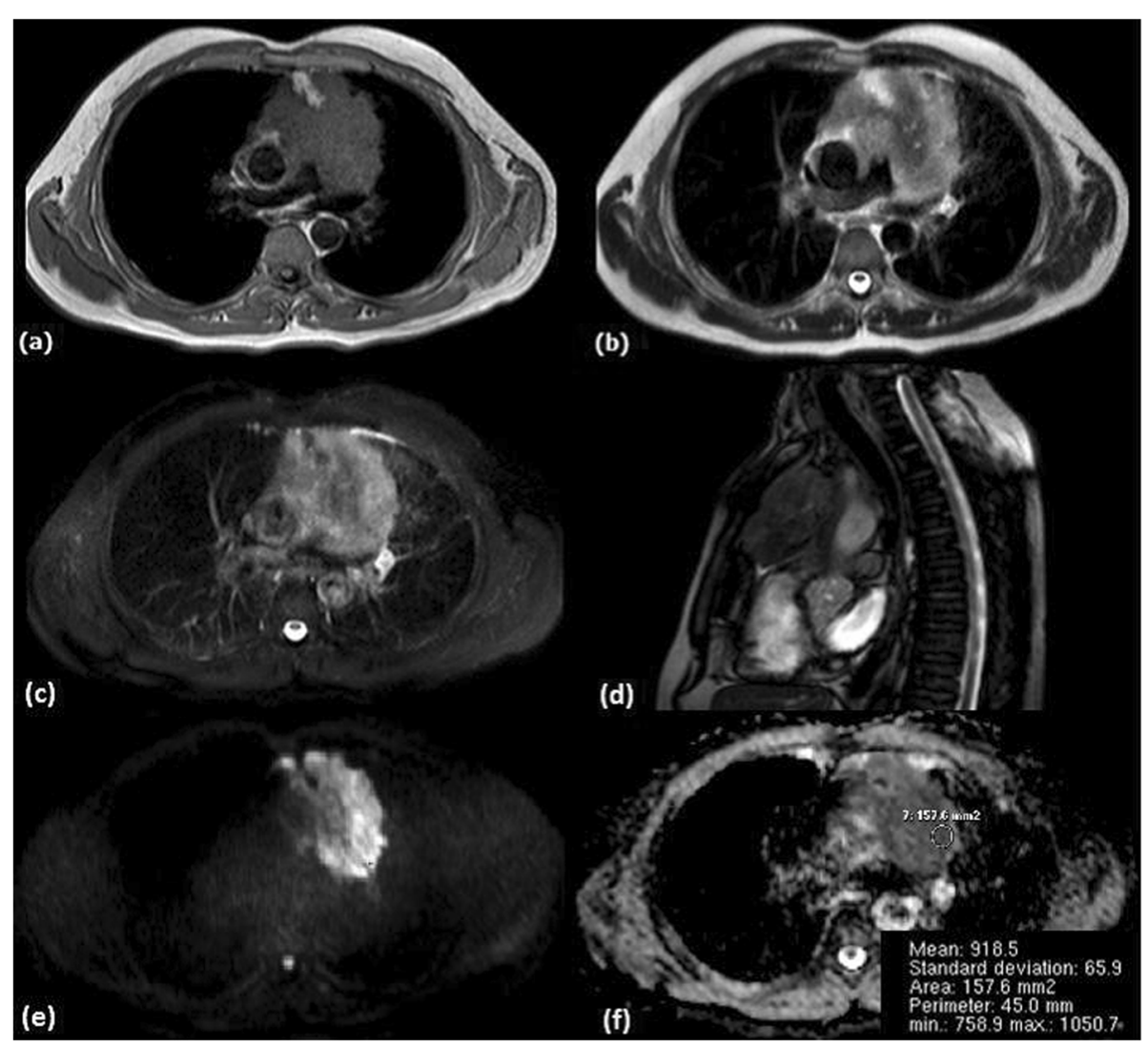

Fig. 6 Hodgkin lymphoma: A 51-year-old male with an anterior (prevascular) mediastinal mass identified on CT. The patient clinically presented with constitutional symptoms (unexplained fever and weight loss), dyspnea, cough, and retrosternal chest pain. a Axial T1 WI, $\mathbf{b}$ axial T2 WI, c axial STIR WI, and $\mathbf{d}$ sagittal BFFE WI show a well-defined ovoid-shaped anterior mediastinal mass displaying intermediate T1 and heterogeneous T2 and STIR signal intensities. The mass shows restricted diffusion; with the predominant bright areas on the $\mathbf{e}$ DWI corresponding to dark areas on the $\mathbf{f} A D C$ map. $A D C_{\text {mean }}=0.890 \times 10^{-3} \mathrm{~mm}^{2} / \mathrm{s}$ and $A D C_{\text {min }}=0.624 \times 10^{-3} \mathrm{~mm}^{2} / \mathrm{s}$

Box-and-Whisker plot (Fig. 7). However, the statistical significance of this important finding could not be assessed and a cut-off value between these two could not be determined because of the limited number of cases involved.

- Similarly, the ten bronchogenic carcinoma cases in this study were histopathologically classified into non-small-cell lung cancer (NSCLC 60\%) and small-cell lung cancer (SCLC 40\%) (Fig. 8). Average $\mathrm{ADC}_{\text {mean }}$ value of SCLC $(0.855 \pm$ $0.324 \times 10-{ }^{3} \mathrm{~mm}^{2} / \mathrm{s}$ ) was lower than that of $\operatorname{NSCLC}\left(0.936 \pm 0.380 \times 10-^{3} \mathrm{~mm}^{2} / \mathrm{s}\right)$ but their $\mathrm{ADC}_{\text {mean }}$ values showed substantial overlap (Fig. 9).

- DWI failed at characterizing one lesion in this study as a malignant tumor, namely an immature teratoma (germ cell tumor) (Fig. 10). Its soft tissue component showed facilitated diffusion with an $\mathrm{ADC}_{\text {mean }}\left(2.44 \times 10-^{3} \mathrm{~mm}^{2} / \mathrm{s}\right)$ higher than previously reported cut-off ADC values, hence, it was misdiagnosed as a benign lesion.

- Again DWI could not be used to evaluate the mass that was later pathologically diagnosed as an angiosarcoma because of its overall hemorrhagic nature showing no definite non-hemorrhagic soft tissue components (Fig. 11).

- Minimum ADC of each lesion was taken into account when attempting to characterize the different malignant mediastinal lesions included in this study. However, the aforementioned results did not differ considerably when minimum ADC was used instead of mean ADC.

\section{Discussion}

Influenced by the constantly evolving approach to non-invasive patient management in the era of functional imaging, investigators demonstrated the diagnostic potential of DW-MR images and calculated 


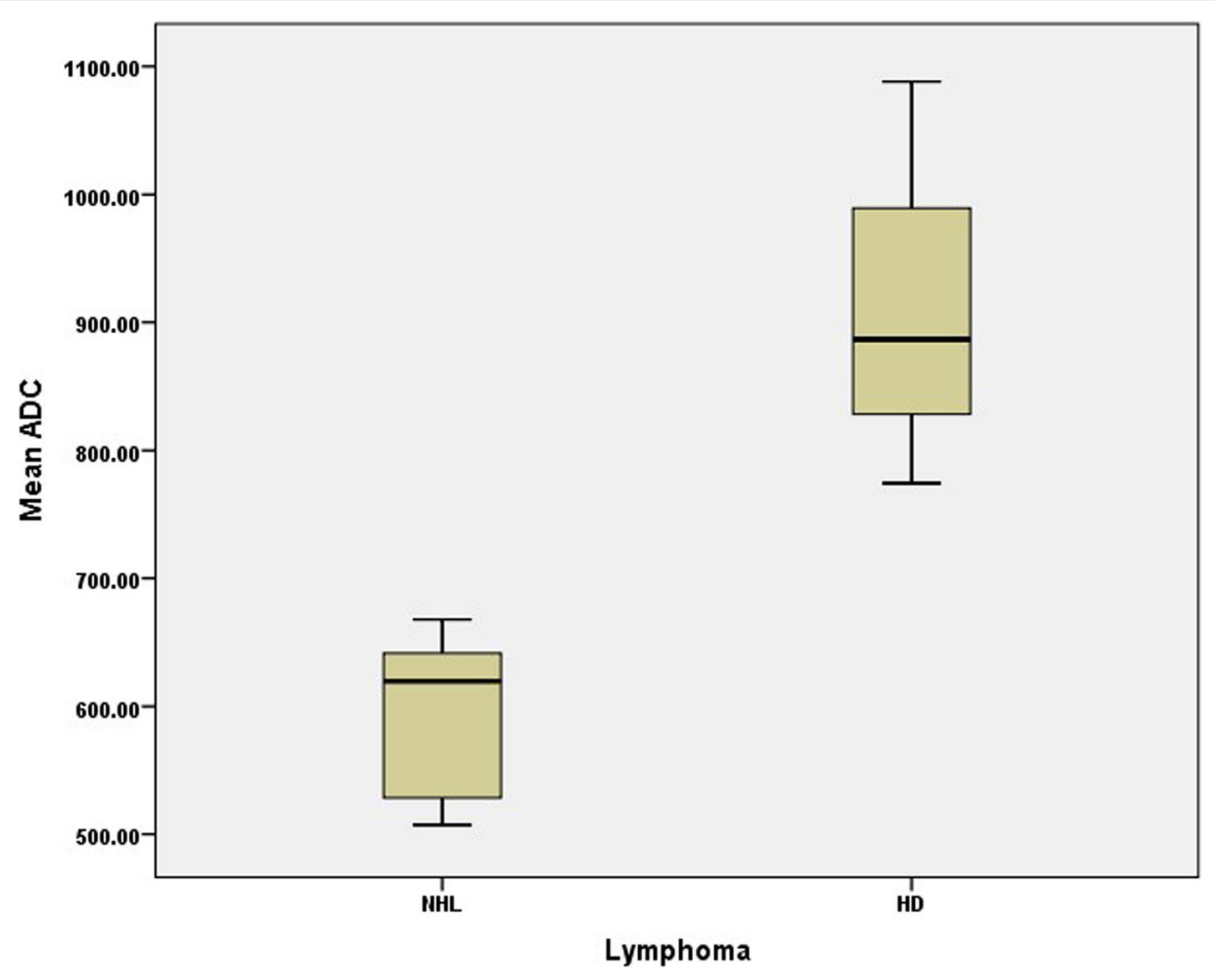

Fig. 7 Bar-and-Whisker plot: $A D C_{\text {mean }}$ values of $\mathrm{NHL}$ and $\mathrm{HD}$

ADC values to differentiate between benign and malignant tumors including those of the mediastinum. Hence, serving as a virtual biopsy and in some cases preventing unnecessary diagnostic intervention.

Conducted studies showed that the ADC values of malignant mediastinal lesions are significantly lower than those of benign lesions and determined cut-off ADC values to differentiate the two.

Taking this a step forward, the main purpose of our prospective study was to investigate the potential of DW-MRI to characterize malignant mediastinal lesions using their ADC values.

The study included 33 patients with a mediastinal mass identified on CT that underwent MRI of the chest with DWI and were later histopathologically diagnosed with a malignant mediastinal lesion. Patients were grouped according to their histopathological diagnosis.

There was no statistically significant difference between the ADCmean values of the histopathological groups of lesions assessed. This is in concordance with the study carried out by Tondo et al., 2011 who found substantial overlap in ADCmean values of all examined malignant lesions $(n=30)$, namely bronchogenic carcinoma, thymic carcinoma, and malignant teratoma [16].
Moreover, the 32 malignant mediastinal lesions studied by Nasr et al., 2016 included lymphoma, bronchogenic carcinoma, invasive thymoma, and metastases. No significant difference between their ADCmean values was found as well [11].

Likewise, the 30 malignant mediastinal tumors in Abdel Razek et al., 2009s study were lymphoma, bronchogenic carcinoma, invasive thymoma, and angiosarcoma and again difference between their ADCmean values was insignificant with evident overlapping of the ADC values of lymphoma, bronchogenic carcinoma, and thymoma [13].

These findings may be attributed to a relatively small sample size and/or heterogeneity of the histopathological subtypes of malignant mediastinal lesions evaluated.

In agreement with Nasr et al., there was no statistically significant difference between the $\mathrm{ADC}_{\text {mean }}$ values of lymphoma and the $\mathrm{ADC}_{\text {mean }}$ values of the rest of the histopathological groups conjointly. Tondo et al., 2011 reported similar results to ours where no significant difference was found between bronchogenic carcinoma (adenocarcinomas) and malignant mediastinal lesions in their study $[11,16]$.

On comparing the ADCmean values of lymphoma and bronchogenic carcinoma, lesions most frequently 


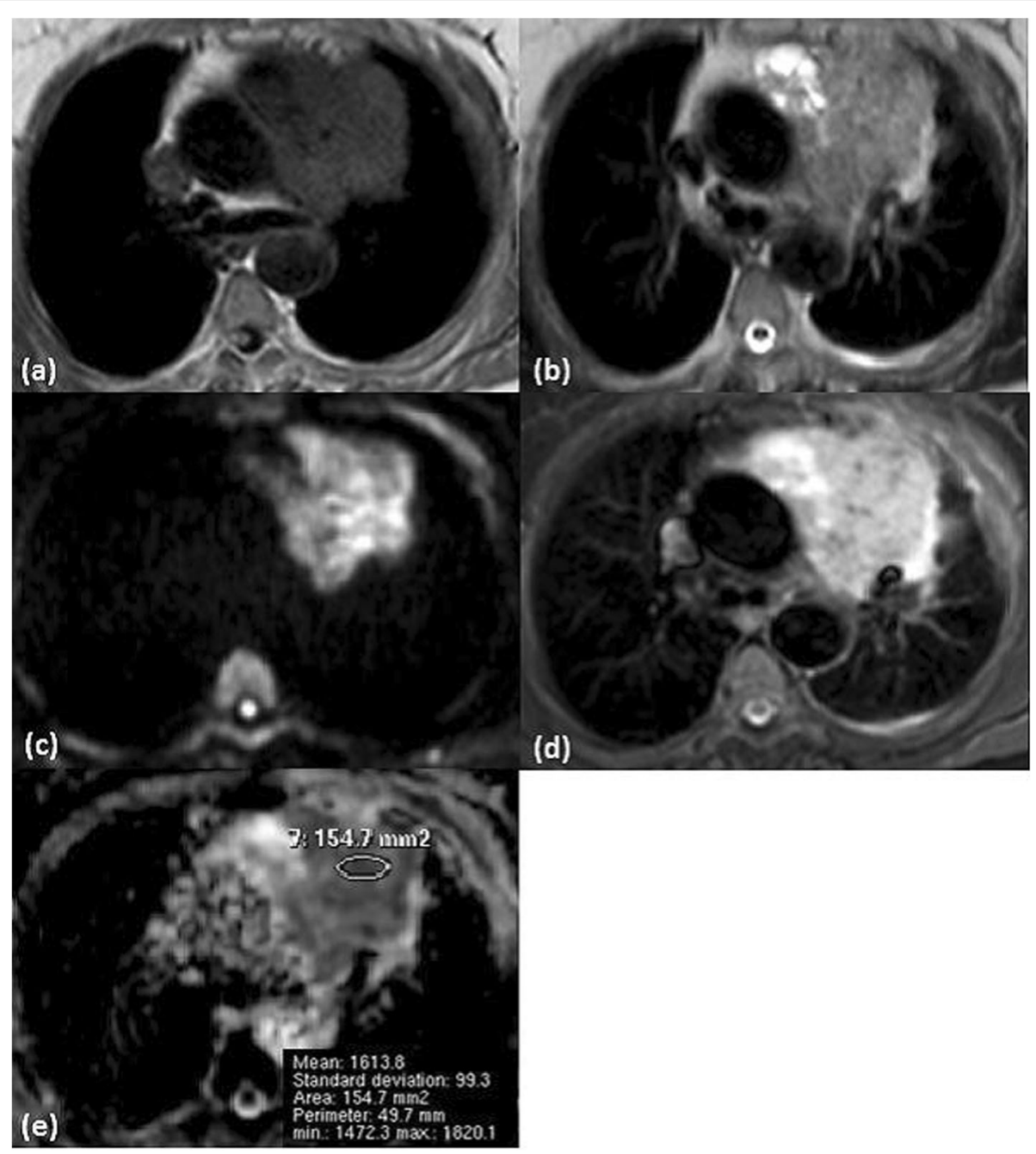

Fig. 8 Squamous cell carcinoma of lung origin (bronchogenic carcinoma: NSCLC): A 62-year-old female clinically presenting with cough, dyspnea and chest pain underwent MDCT of the chest that revealed an anterior mediastinal mass. a Axial T1 WI, b axial T2 WI and d axial STIR WI show a well-defined rather ovoid-shaped anterior mediastinal mass displaying intermediate T1 and relatively bright T2 and STIR signal intensities. Small areas of breaking down exhibiting low T1 and bright T2 and STIR signal intensities are noted. The lesion (sparing the small areas of breaking down) shows restricted diffusion by being bright on $\mathbf{c} D W I$ and dark on the e $\mathrm{ADC}_{\mathrm{map}}$. $\mathrm{ADC}_{\text {mean }}=$ $1.63 \times 10^{-3} \mathrm{~mm}^{2} / \mathrm{s}$ and $A D C_{\min }=1.47 \times 10^{-3} \mathrm{~mm}^{2} / \mathrm{s}$

encountered in our study, the difference between their ADCmean values was statistically insignificant as well. Among the 26 malignant lesions prospectively studied by Gümüştaş et al., 2011, 11 were bronchogenic carcinoma (NSCLC) and 9 were lymphoma. When their ADCmean values were compared, no significant difference was found with an overlap between these two subgroups; results similar to ours. However, Maeda et al., 2005, Abdel Razek et al., 2006, Sumi et al., 2007, Holzapfel et al., 2009 and Kato et al. 2015 reported that the ADC of lymphoma is significantly lower than that of squamous cell carcinoma of the head and neck [14, 18-22].
Anterior mediastinal lesions "most importantly lymphoma, thymic, and germ cell tumors" in our study were entitled to be evaluated separately and again difference between their ADC values was statistically insignificant. Yabuuchi et al., 2015 conducted a retrospective study in the search of significant parameters to characterize anterior mediastinal tumors; one of the parameters evaluated was tumors' ADC value. Malignant anterior mediastinal lesions included in their study were thymic epithelial tumors (malignant thymoma and thymic carcinoma), lymphoma, and germ cell tumors. In agreement with our results, there was no significant 


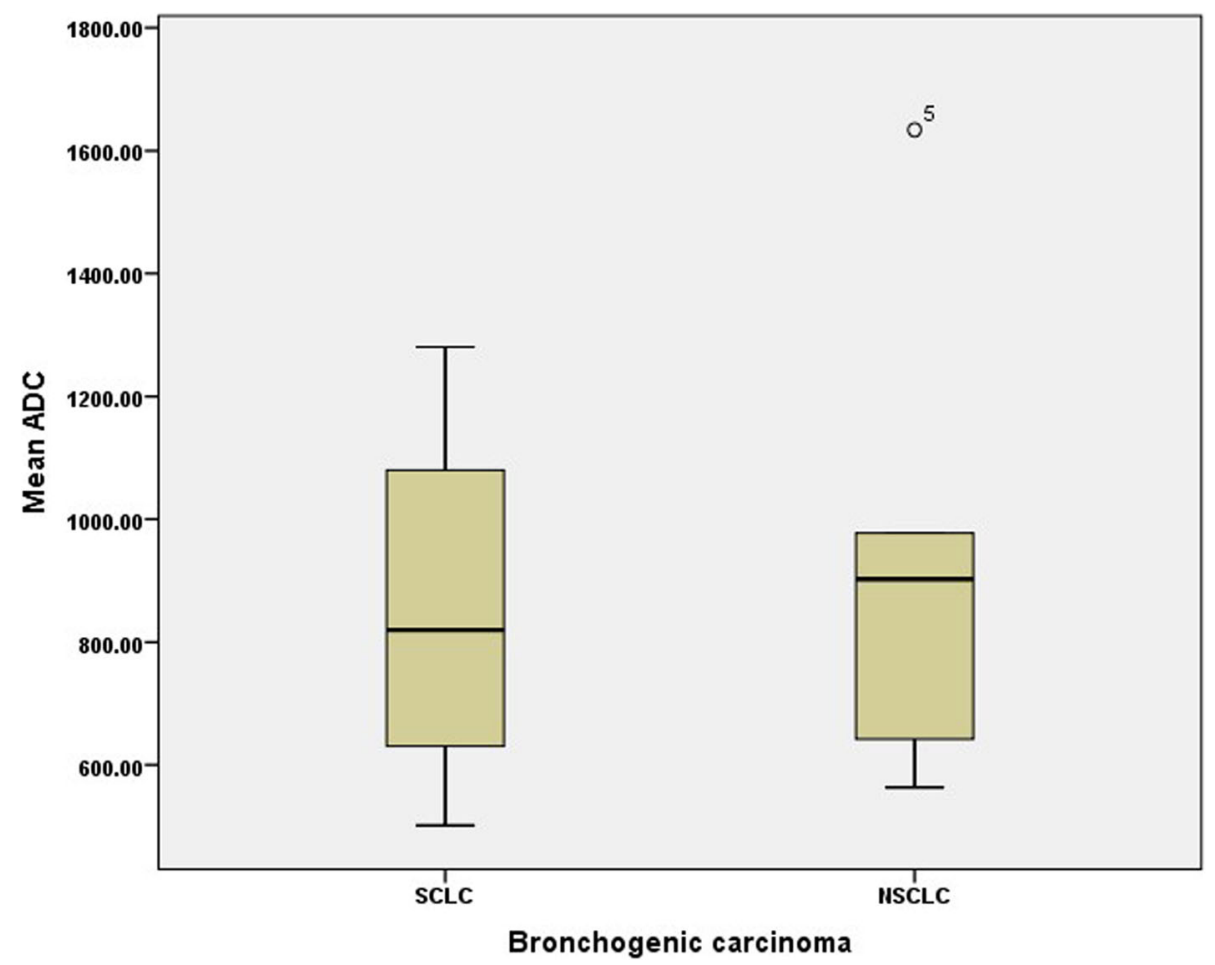

Fig. 9 Bar-and-Whisker plot: $A D C_{\text {mean }}$ values of SCLC and NSCLC

difference between the ADC of these histopathological subtypes at both initial and validation studies [23].

Regarding the pathological subtypes of lymphoma; in the retrospective study of mediastinal lymphadenopathy in children by Abdel Razek et al., 2015, the average ADCmean of NHL was lower than that of HD-results similar to ours-but the difference between the two was insignificant. On searching the literature, no attempts at using DWI to differentiate between lymphoma subtypes, in particular, were found [24].

A meta-analysis of 34 studies (conducted in the years 2007 to 2014) involving 2086 patients with pulmonary lesions was recently performed by Shen et al., 2016. One of their objectives was to evaluate the role of $\mathrm{ADC}$ in characterizing subtypes of lung cancer. Pooled ADC values of SCLC were significantly lower than those of NSCLC, which to an extent agrees with our study (results more or less similar to ours). The potential histopathological rationale might be that SCLC has high tumoral cellularity, large nuclei, and almost no cytoplasm, all of which restrict the diffusion of water molecules thereby reducing ADC values [25].

Limited data are available on quantitative assessment of thymic epithelial tumors (TETs) by using DW-MRI from small cohorts of studies which considered various anterior mediastinal tumors. Not to mention that those studies did not attempt to differentiate thymomas based on WHO and Masaoka-Koga classifications by using ADC. Recently, a study by Abdel Razek et al. involving 30 patients with TETs has demonstrated the ability of ADC in differentiating low-risk from high-risk tumors, and early from advanced disease. Mean ADC values of high-risk thymomas and advanced stage TETs were significantly lower than those of lowrisk thymomas and early-stage TETs respectively. They determined cut-off mean ADC values of 1.22 $\mathrm{mm}^{2} / \mathrm{s}$ and $1.25 \mathrm{~mm}^{2} / \mathrm{s}$ below which a high-risk thymoma is indicated. In a relatively similar study by Priola et al., accurate cut-off mean ADC values of $1.309 \times 10{ }^{3} \mathrm{~mm}^{2} / \mathrm{s}$ and $1.243 \times 10{ }^{3} \mathrm{~mm}^{2} / \mathrm{s}$ were determined below which a high-risk thymoma and an advanced stage TET are indicated respectively. Moreover, mean ADC of B3 thymoma was significantly lower than that of B2 thymoma. ADC levels were significantly associated with disease-free survival of patients with a recurrence rate being higher for patients with ADC $\leq 1.299 \times 10^{-3} \mathrm{~mm}^{2}$ / s. To conclude, ADC helps to differentiate high-risk from low-risk thymomas and may be used as a prognostic indicator of recurrence, yet further studies are needed to validate these results [26, 27]. 


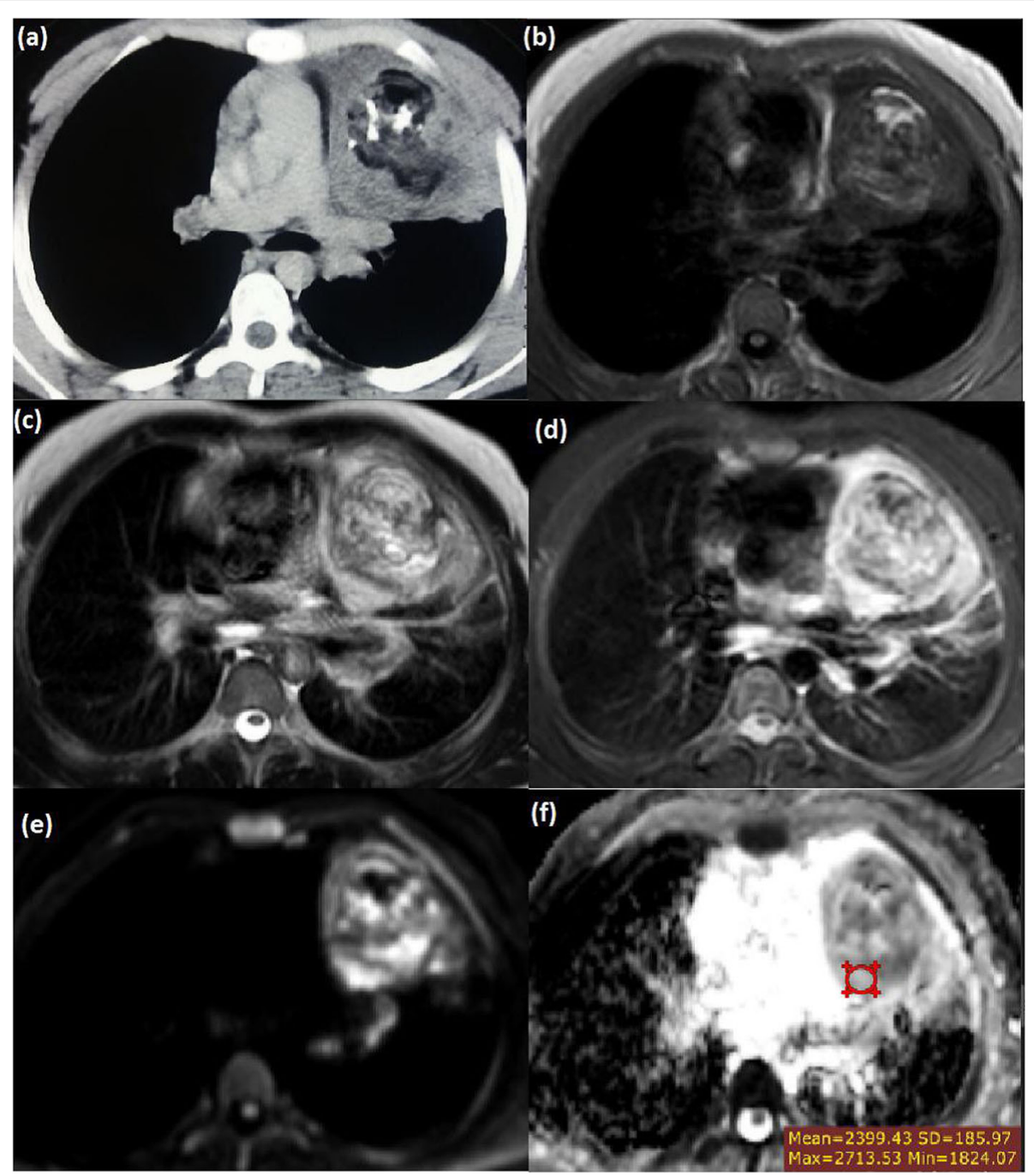

Fig. 10 Grade I immature (malignant) teratoma (pathologically proven after thoracotomy and complete excision-excised lymph nodes: free): A 13-year-old male with an anterior mediastinal (prevascular) mass identified on CT. The patient clinically presented with mild chest pain (discomfort). b Axial T1 WI, c axial T2 WI, and $\mathbf{d}$ axial STIR WI show a well-defined rather wedge-shaped anterior mediastinal mass displaying overall heterogeneous signal on all pulse sequences by virtue of its fat and calcific components (confirmed by referring to a axial MDCT of the chest in mediastinal window). Associated findings: Lingular collapse and small prevascular and left hilar lymph nodes, largest measures $1.5 \mathrm{~cm}$. Lesion's soft tissue component shows facilitated diffusion. It displays bright signal on e DWI seen corresponding to bright signal on the $\mathbf{f} A D C$ map: $A D C_{\text {mean }}=2.44 \times 10^{-3} \mathrm{~mm} 2 / \mathrm{s}$ and $A D C_{\text {min }}=1.701 \times 10-^{3} \mathrm{~mm}^{2} / \mathrm{s}$

Nasr et al., 2016, Usuda et al.,2015, Tondo et al., 2011, Gümüştaş et al., 2011 and Abdel Razek et al., 2009 conducted prospective/retrospective studies to quantitatively assess and differentiate benign and malignant mediastinal lesions using DWI. They determined highly sensitive and specific cut-off ADC values below which a malignant mediastinal lesion is indicated; $1.15 \times 10-^{3}, 2.21 \times 10-^{3}, 1.25 \times 10-^{3}$, $1.39 \times 10-^{3}$, and $1.56 \times 10-^{3} \mathrm{~mm}^{2} / \mathrm{s}$ respectively. One lesion, namely a malignant teratoma had an $\mathrm{ADC}_{\text {mean }}$ evidently higher than these cut-off $\mathrm{ADC}$ values $\left(\right.$ ADCmean $\left.=2.44 \times 10-^{3} \mathrm{~mm}^{2} / \mathrm{s}\right)$ and was hence mistaken for a benign lesion. This may be explained by the fact that when the mass was surgically excised, it proved malignant only by the presence of microscopic foci of immature neuroepithelial component $[11,13,14,16,17]$.

The one lesion pathologically diagnosed as an angiosarcoma was overall hemorrhagic in nature with no sizeable non-hemorrhagic soft tissue components seen on the conventional MR images rendering a qualitative assessment of the DWI and ADC measurement not 


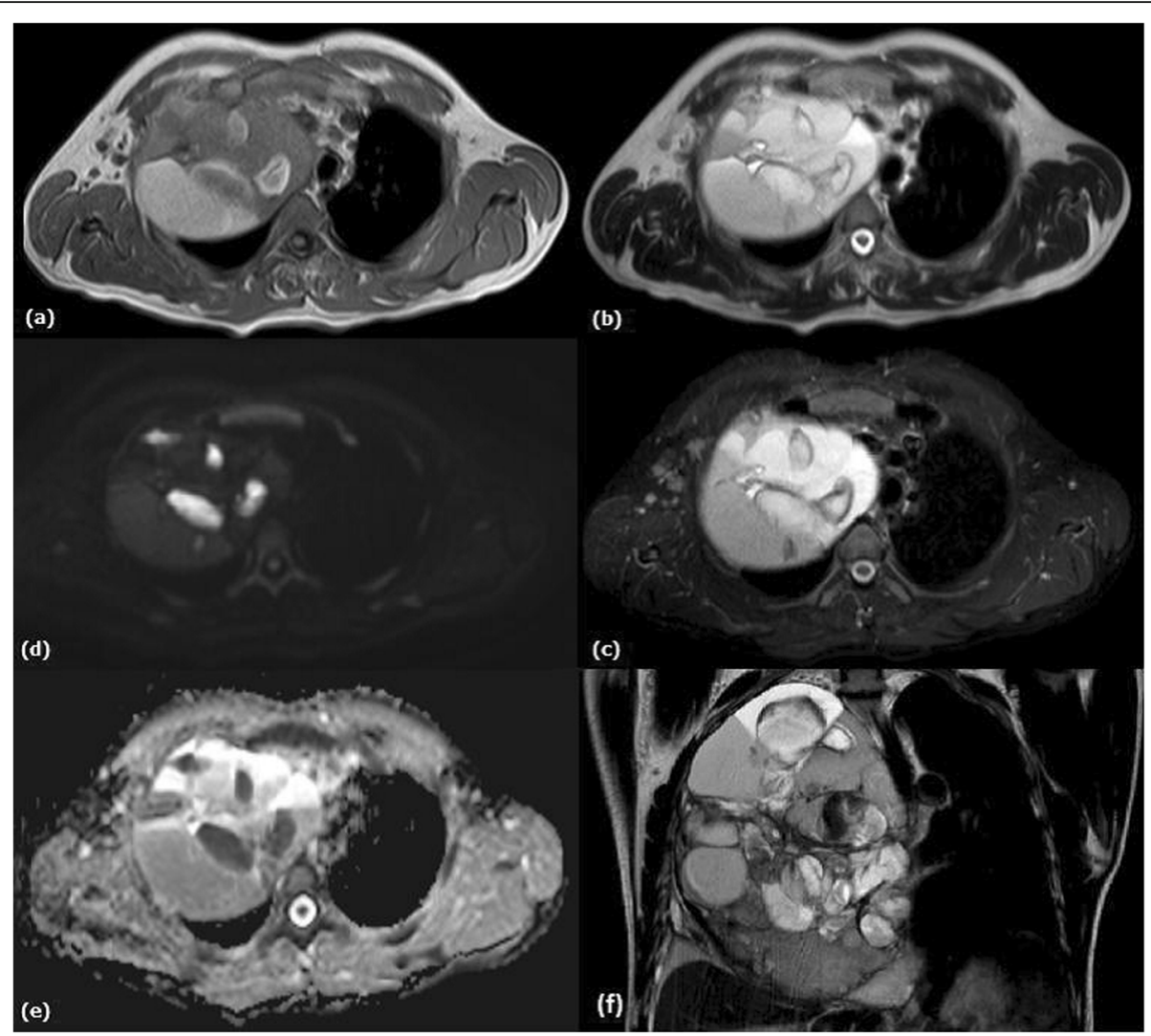

Fig. 11 Angiosarcoma (pathologically proven after thoracotomy and complete excision): A 33-year-old male patient clinically presented with cough, dyspnea, chest pain, and congested neck veins. He underwent MDCT of the chest that revealed an anterior mediastinal mass encroaching upon the right hemithorax. a Axial T1 WI, b and $\mathbf{f}$ axial and coronal T2 WI and c STIR WI show a large well-defined rather ovoid-shaped anterior mediastinal mass encroaching upon and occupying most of the right hemithorax. It displays heterogeneous signal on all pulse sequences with fluid-fluid levels reflecting different ages of blood with no sizeable non-hemorrhagic solid components. A contralateral shift of the mediastinum is noted. Associated findings: ipsilateral pleural thickening and minimal pleural effusion. $\mathbf{d}$ DWI and e ADC map: not assessed because of the lesion's overall hemorrhagic nature with no definite soft tissue components as apparent on the conventional MR images

possible. This was based on the fact stated by Qayyum, 2009: blood demonstrates signal characteristics of highly cellular soft tissue lesions; a pitfall readily observed on DWI [7].

A number of authors recommended that minimum $\mathrm{ADC}$ is used instead of mean ADC when quantitatively assessing a lesion since it theoretically reflects the area of highest tumor cellularity and unlike mean ADC, it would not underestimate tumor cellularity in the context of a largely necrotic tumor [28]. Accordingly, a minimum ADC of each lesion was taken into account when attempting to characterize the different malignant mediastinal lesions included in this study. However, the aforementioned results did not differ considerably when minimum ADC was used instead of mean ADC. Nevertheless, most published studies that evaluated mediastinal lesions using DWI referred to mean and not minimum ADC values.

\section{Conclusion}

Although highly sensitive and specific cut-off ADC values to distinguish benign and malignant mediastinal lesions were published, in this study, DWI could not be used to characterize the histopathological subtypes of malignant mediastinal lesions. However, regarding lymphoma subtypes, our limited sample study of lymphoma suggested a considerable difference between the ADC values of Hodgkin disease and non-Hodgkin lymphoma.

\section{Abbreviations}

ADC: Apparent diffusion coefficient; $A D C_{\text {mean: }}$ Mean apparent diffusion coefficient; $A D C_{\text {min }}$ : Minimum apparent diffusion coefficient; ANOVA: Analysis of variance; CT: Computed tomography; DW-MRI: Diffusion-weighted magnetic resonance imaging; HD: Hodgkin disease; ITMIG: International Thymic Malignancy Interest Group; MRI: Magnetic resonance imaging; n: Number; NHL: Non-Hodgkin lymphoma; NSCLC: Non-small cell lung cancer; ROI: Region of interest; SCLC: Small-cell lung cancer; SPSS: Statistical 
Package for the Social Sciences; STIR: Short tau inversion recovery; TETs: Thymic epithelial tumors; U/S: Ultrasound; WI: Weighted image

\section{Acknowledgements}

Not applicable.

\section{Authors' contributions}

YYS, EZN, and HSW reviewed all patients' magnetic resonance images. EZN analyzed and interpreted the patient data. EZN wrote the manuscript. All authors read and approved the final manuscript.

\section{Funding}

Not applicable (no funding was provided).

\section{Availability of data and materials}

The datasets used and/or analyzed during the current study are available from the corresponding author on reasonable request.

\section{Ethics approval and consent to participate}

Institutional (Faculty of Medicine 'Kasr El-Ainy Hospital' and National Cancer Institute, Cairo University) ethical clearance was taken before conducting this prospective study; March 2016_Reference number: not available. Written consent was obtained from patients or their authorized representatives.

\section{Consent for publication}

All patients included in this research gave written informed consent to publish the data contained within this study. If the patient was less than 16 years old, deceased, or unconscious when consent for publication was requested, written informed consent for the publication of this data was given by their parent or legal guardian.

\section{Competing interests}

The authors declare that they have no competing interests.

\section{Author details}

${ }^{1}$ Radiodiagnosis, Faculty of Medicine, Cairo University, Cairo, Egypt. ${ }^{2}$ Radiodiagnosis, National Hepatology and Tropical Medicine Research Institute (NHTMRI), 10 (A) Kasr El-Aini St, Cairo, Egypt. ${ }^{3}$ Pulmonology, Faculty of Medicine, Cairo University, Cairo, Egypt. ${ }^{4}$ Radiodiagnosis, National Cancer Institute, Cairo University, Cairo, Egypt.

\section{Received: 31 October 2019 Accepted: 5 January 2020}

Published online: 11 February 2020

\section{References}

1. Carter BW, Okumura M, Detterbeck FC, Marom EM (2014) Approaching the patient with an anterior mediastinal mass: a guide for radiologists. J Thorac Oncol 9(9):S110-S118 https://doi.org/10.1097/JTO.0000000000000295

2. Juanpere S, Cañete N, Ortuño P, Martínez S, Sanchez G, Bernado L (2013) A diagnostic approach to the mediastinal masses. Insights Imaging 4(1):29-52 https://doi.org/10.1007/s13244-012-0201-0

3. Thacker PG, Mahani MG, Heider A, Lee EY (2015) Imaging evaluation of mediastinal masses in children and adults: practical diagnostic approach based on a new classification system. J Thorac Imaging 30(4):247-267 https://doi.org/10.1097/RTI.0000000000000161

4. Carter BW, Benveniste MF, Madan R, Godoy MC, de Groot PM, Truong MT et al (2017) ITMIG classification of mediastinal compartments and multidisciplinary approach to mediastinal masses. Radiographics 37(2):413436 https://doi.org/10.1148/rg.2017160095

5. Whitten CR, Khan S, Munneke GJ, Grubnic S (2007) A diagnostic approach to mediastinal abnormalities. Radiographics 27(3):657-671 https://doi.org/10. 1148/rg.273065136

6. Carter BW, Betancourt SL, Benveniste MF (2017) MR imaging of mediastinal masses. Top Magn Reson Imaging 26(4):153-165

7. Qayyum A (2009) Diffusion-weighted Imaging in the abdomen and pelvis: concepts and applications. Radiographics 29(6):1797-1810 https://doi.org/ 10.1148/rg.296095521

8. Taouli B, Koh D-M (2010) Diffusion-weighted MR imaging of the liver. Radiology 254(1):47-66 https://doi.org/10.1148/radiol.09090021

9. Ackman JB (2015) MR imaging of mediastinal masses. Magn Reson Imaging Clin N Am 23(2):141-164 https://doi.org/10.1016/j.mric.2015.01.002
10. Luna A, Sánchez-Gonzalez J, Caro P (2011) Diffusion-weighted imaging of the chest. Magn Reson Imaging Clin N Am 19(1):69-94 https://doi.org/10. 1016/j.mric.2010.09.006

11. Nasr A, Elshahat $H$, Safwat $H$, Alsaif $R$, Alshehab D, Shebl M (2016) Diffusion weighted MRI of mediastinal masses: can measurement of ADC value help in the differentiation between benign and malignant lesions. Egypt J Radiol Nuc Med 47(1):119-125 https://doi.org/10.1016/j. ejrnm.2015.12.002

12. Shin KE, Yi CA, Kim TS, Lee HY, Choi YS, Kim HK, Kim J (2014) Diffusionweighted MRI for distinguishing non-neoplastic cysts from solid masses in the mediastinum: problem-solving in mediastinal masses of indeterminate internal characteristics on CT. Eur Radiol 24(3):677-684 https://doi.org/10. 1007/s00330-013-3054-0

13. Abdel Razek AAK, Elmorsy A, Elshafey M, Elhadedy T, Hamza O (2009) Assessment of mediastinal tumors with diffusion-weighted single-sho echo-planar MRI. J Magn Reson Imaging 30(3):535-540 https://doi.org/10. 1002/jmri.21871

14. Gümüştaş S, Inan N, Sarisoy HT, Anik Y, Arslan A, Çiftçi E et al (2011) Malignant versus benign mediastinal lesions: quantitative assessment with diffusion weighted MR imaging. Eur Radiol 21(11):2255-2260 https://doi. org/10.1007/s00330-011-2180-9

15. Sabri YY, Kolta MFF, Khairy MA (2017) MR diffusion imaging in mediastinal masses the differentiation between benign and malignant lesions. Egypt J Radiol Nucl Med 48(3):569-580 https://doi.org/10.1016/j. ejrnm.2017.03.015

16. Tondo F, Saponaro A, Stecco A, Lombardi M, Casadio C, Carriero A (2011) Role of diffusion-weighted imaging in the differential diagnosis of benign and malignant lesions of the chest-mediastinum. Radiologia Medica 116(5): 720-733 https://doi.org/10.1007/s11547-011-0629-1

17. Usuda K, Maeda S, Motono N, Ueno M, Tanaka M, Machida Y et al (2015) Diffusion weighted imaging can distinguish benign from malignant mediastinal tumors and mass lesions: Comparison with positron emission tomography. Asian Pac J Cancer Prev 16(15):6469-6475 https://doi.org/10. 7314/APJCP.2015.16.15.6469

18. Abdel Razek AAK, Soliman NY, Elkhamary S, Alsharaway MK, Tawfik A (2006) Role of diffusion-weighted MR imaging in cervical lymphadenopathy. Eur Radiol 16(7):1468-1477 https://doi.org/10.1007/s00330-005-0133-x

19. Holzapfel K, Duetsch S, Fauser C, Eiber M, Rummeny EJ, Gaa J (2009) Value of diffusion-weighted MR imaging in the differentiation between benign and malignant cervical lymph nodes. Eur J Radiol 72(3):381-387 https://doi. org/10.1016/j.ejrad.2008.09.034

20. Kato H, Kanematsu M, Watanabe H, Kawaguchi S, Mizuta K, Aoki M (2015) Differentiation of extranodal non-Hodgkins lymphoma from squamous cell carcinoma of the maxillary sinus: a multimodality imaging approach. Springerplus 4(1):228 https://doi.org/10.1186/s40064-015-0974-y

21. Maeda M, Kato H, Sakuma H, Maier SE, Takeda K (2005) Usefulness of the apparent diffusion coefficient in line scan diffusion-weighted imaging for distinguishing between squamous cell carcinomas and malignant lymphomas of the head and neck. AJNR Am J Neuroradiol 26(5):1186-1192

22. Sumi M, Ichikawa Y, Nakamura T (2007) Diagnostic ability of apparent diffusion coefficients for lymphomas and carcinomas in the pharynx. Eur Radiol 17(10):2631-2637 https://doi.org/10.1007/s00330-007-0588-z

23. Yabuuchi H, Matsuo Y, Abe K, Baba S, Sunami S, Kamitani T et al (2015) Anterior mediastinal solid tumors in adults: characterization using dynamic contrast-enhanced MRI, diffusion-weighted MRI, and FDG-PET/CT. Clin Radiol 70(11):1289-1298 https://doi.org/10.1016/j. crad.2015.07.004

24. Abdel Razek AAK, Gaballa G, Elashry R, Elkhamary S (2015) Diffusionweighted MR imaging of mediastinal lymphadenopathy in children. Jap J Radiol 33(8):449-454 https://doi.org/10.1007/s11604-015-0434-1

25. Shen G, Jia Z, Deng H (2016) Apparent diffusion coefficient values of diffusion-weighted imaging for distinguishing focal pulmonary lesions and characterizing the subtype of lung cancer: a meta-analysis. Eur Radiol 26(2): 556-566 https://doi.org/10.1007/s00330-015-3840-y

26. Abdel Razek AAK, Khairy M, Nada N (2014) Diffusion-weighted MR imaging in thymic epithelial tumors: correlation with World Health Organization Classification and Clinical staging. Radiology 273(1):268-275 https://doi.org/ 10.1148/radiol.14131643

27. Priola AM, Gned D, Veltri A, Priola SM (2016) Chemical shift and diffusionweighted magnetic resonance imaging of the anterior mediastinum in 
oncology: current clinical applications in qualitative and quantitative assessment. Crit Rev Oncol Hematol 98:335-357 https://doi.org/10.1016/j. critrevonc.2015.11.012

28. Subhawong TK, Jacobs MA, Fayad LM (2014) Diffusion-weighted MR imaging for characterizing musculoskeletal lesions. Radiographics 34(5): 1163-1177 https://doi.org/10.1148/rg.345140190

\section{Publisher's Note}

Springer Nature remains neutral with regard to jurisdictional claims in published maps and institutional affiliations.

Submit your manuscript to a SpringerOpen ${ }^{\circ}$ journal and benefit from:

- Convenient online submission

- Rigorous peer review

- Open access: articles freely available online

High visibility within the field

- Retaining the copyright to your article

Submit your next manuscript at $\boldsymbol{\nabla}$ springeropen.com 